\title{
White paper on radiation protection by the European Society of Radiology
}

\author{
European Society of Radiology (ESR)
}

Received: 16 May 2011 / Accepted: 16 May 2011

(C) European Society of Radiology 2011

\begin{abstract}
In the past decade, the medical effective dose per caput has increased in most European countries because of $\mathrm{CT}$; it now ranges between 0.4 and $2 \mathrm{mSv} /$ year. The biological impact of diagnostic imaging exposure is dominated by stochastic effects: based on the linear-nothreshold hypothesis, the risk of cancer induction is estimated to increase proportionally to organ dose, reaching around $0.5 \%$ at an effective dose of $100 \mathrm{mSv}$. The risk is higher the younger the age at the time of exposure, it is different for different organs, and women are more susceptible than men. Fluoroscopy-based imaging, above all intervention, may reach the dose threshold for deterministic effects, observed most often at the skin above around $3 \mathrm{~Gy}$, and it is also the major source of occupational exposure in radiology. This white paper discusses the role of justification, evidence-based referral guidelines, optimization, diagnostic reference levels, clinical audits and quality assurance programs. The ESR strongly supports education and training of the medical staff involved in imaging by ionizing radiation. It disseminates information regarding radiation protection, takes initiatives, cooperates with partners and supports projects in justification as well
\end{abstract}

\section{Key points}

- The most likely biological impact of imaging using ionizing radiation is carcinogenesis; the ALARA principle has to be applied to every patient.

- Education and training are compulsory prerequisites for radiation protection in clinical radiology.

- Children, potentially pregnant and pregnant women, as well as young adults deserve special caution since young tissue is biologically more sensitive to radiation effects.

European Society of Radiology (ESR) $(\bowtie)$

Neutorgasse $9 / 2$,

1010 Vienna, Austria

e-mail: communications@myESR.org

URL: www.myESR.org as optimization. To reach these aims, the ESR cooperates with other organizations involved in radiation protection.

Keywords Radiation protection $\cdot$ Cancer risk $\cdot$ Imaging

\section{Introduction}

The rising use of medical imaging has enhanced the quality of health care and convinced even those critical clinicians that initially had relied more on the clinical examination than on imaging data. The potential stochastic and even deterministic detriments of ionizing radiation to humans have become widely discussed in medicine, among patients, in the media and even by politicians. It is essential that radiologists should be fully aware of these detriments, to objectively understand their scientific basis and to apply medical diagnostic and interventional radiation carefully, weighing the benefits with the risks, and to help the community to achieve the best use of imaging tools. Therefore, radiation protection has become a top priority of the European Society of Radiology (ESR). This white paper will summarize the facts and overview the activities needed in modern radiation protection.

Radiation exposure of the European population, global and medical

The global per caput effective dose ranges widely, with western countries showing rather low values of $2.7 \mathrm{mSv} /$ year (UK) or $4 \mathrm{mSv} /$ year (Germany); in many countries, depending on the local geology, radon and thorium are the largest natural sources of exposure, far ahead of cosmic and internal radiation. Civilization mainly contributes by medical exposure and a number of sources, such as nuclear power reactors and professional exposure. Eastern European countries, 
mostly because of the Chernobyl accident, may have significantly higher exposure.

Data collected over the last 12 years show a medical effective dose per caput of three ranges: low exposure in the UK, the Netherlands and Sweden (0.4-0.75 mSv/year), intermediate exposure in Norway and Switzerland (1.1 mSv/y), and higher exposure in Luxemburg, Belgium and Germany (1.8-2.0 mSv/year). Over the years, there has been a universal trend of increasing medical exposure, mostly caused by CT. Nuclear medicine, currently accounting for around $7 \%$ of the total medical exposure (Germany), may become much more important with the increasing use of PET. In some countries the medical contribution to the population dose is in the range of $50 \%$, similar to the USA.

\section{Biological impact of radiation exposure}

The radiation effects are classified into "stochastic effects," increasing the probability of cancer induction, and "deterministic effects", e.g., skin burns. In the dose range used in diagnostic radiology, epidemiology is unable to produce clear evidence of the "stochastic" cancer risk. For this reason, the rate of cancer induction is estimated by extrapolation from observations based on higher radiation doses using the linear-no-threshold hypothesis. Repeated examinations will add up and proportionally increase the risk. The risk of hereditary effects to the germ cells seems to be much smaller than the risk of cancer induction. It is assumed that roughly $5 \%$ of a population exposed to $1 \mathrm{~Sv}$ of effective dose will develop cancer during their lifetime, usually after a latency period of years to decades; in children, young adults and during pregnancy - with biologically more sensitive tissue - the risk is significantly higher, while in the population of western European patients with a peak age of $60-70$ years, it is reduced to $2-3 \%$ because of the age-related lower biological impact of ionizing radiation. While the vast majority of diagnostic examinations will never reach the threshold for deterministic effects, fluoroscopy-based angiography and minimally invasive interventional treatments often require long periods of fluoroscopy and large numbers of spot exposures; the local dose, mainly of the skin, may reach the threshold of roughly 3 Gy for erythema and more severe skin damage (Table 1).

Medical exposure of the individual patient

In diagnostic radiology, the detriment arising from $\mathrm{x}$-ray examinations can be stochastic or non-stochastic (deterministic) and depends upon the radiation dose to individual organs or tissues. Consequently, the dose to individual organs and tissues must be quantified, with an acceptable level of uncertainty, in order to assess the detriment; this is usually the task of a medical physicist. In cooperation with the clinical team, the radiation dose is determined either with measurements using suitable detectors and phantoms, and/or Monte Carlo simulations of the energy deposition from an x-ray examination. The dose values to important critical organs and tissues are weighted and summed to give the effective dose as defined by the International Commission on Radiological Protection (ICRP), an estimate of a whole body dose causing the same biological impact as the specific heterogeneous exposure. Organ doses can be used as an estimate for a possible cancer induction rate from a diagnostic procedure for a population. With the exception of localized skin dose, it is difficult to measure tissue doses directly, and instead quantities that can be measured directly, in combination with absorbed dose conversion coefficients, are used. Thus, the estimate of the tissue or organ dose is the measured quantity multiplied by the absorbed dose conversion coefficient. Thus, the Computed Tomographic Dose Index (CTDI) is a CT dose quantity that can be measured with a pencil ionization chamber inserted into a phantom that imitates a patient's body. Organ dose CTDI coefficients have been published and serve to convert CTDI values into corresponding patient organ doses. In other words, the appropriate choice of the quantity by which to measure a dose directly is technique specific; therefore, applicationspecific quantities result. These also serve for quality control and the specification of diagnostic reference levels (see below, point 8). The International Atomic Energy Authority (IAEA, www.iaea.org) promotes a scientifically based international code of practice for dosimetry in diagnostic radiology, which standardizes and harmonizes

Table 1 Deterministic radiation effects

\begin{tabular}{llll}
\hline Effect & Threshold (Gy) & $\begin{array}{l}\text { Time normal } \\
\text { fluoroscopy }(0.02 . \text { Gy } / \mathrm{min})\end{array}$ & $\begin{array}{l}\text { Time high-quality } \\
\text { fluoroscopy }(0.2 \mathrm{~Gy} / \mathrm{min})\end{array}$ \\
\hline Skin, erythema & $3-5$ & $150-250 \mathrm{~min}$ & $15-25 \mathrm{~min}$ \\
Skin, ulcer & $10-20$ & $500-100 \mathrm{~min}$ & $50-100 \mathrm{~min}$ \\
Skin, atrophy/fibrosis & $>10$ & $>500 \mathrm{~min}$ & $>50 \mathrm{~min}$ \\
Lens, cataract & 0.5 & $50-100 \mathrm{~min}$ & $5-10 \mathrm{~min}$ \\
\hline
\end{tabular}


the measurement of dose and dose indicators in this field, including guidance for direct measurement on patients or phantoms and indirect measurements on patients or phantoms. The gender and the age at exposure are additional modifiers of the individual biological risk.

\section{Occupational medical exposure}

Occupational exposure basically goes parallel with patient exposure in those applications where staff work inside the examination room, and this is primarily the case for fluoroscopic intervention and secondarily for CT-guided intervention. Thus, the radiologist achieving the lowest patient exposure in similar patients and applications will usually also receive the lowest professional exposure, based on short fluoroscopy time, pulsed fluoroscopy, a low number of high-quality exposures and the optimal selection of technical parameters. Despite this general rule, exact knowledge of the specific equipment is required to choose the best position for all people inside the room (interventionalist, technician/nurse, anaesthetist) to optimally apply modifications of technical parameters and to anticipate their effect on exposure. Furthermore, protection devices for the trunk of the body, the thyroid gland and the eye lenses are required to keep the dose to critical organs and tissues within (and hopefully much below) the legal allowances. Skin dose to the hand mostly depends on the time of direct exposure, and the protective effect of protective gloves is rather limited.

\section{Justification in medicine}

According to the International Commission on Radiological Protection (ICRP), justification has to be done at three levels: in general for the method, specifically for evaluating a clinical suspicion/entity, and individually for the current patient and her/his complete medical, psychological and social situation.

Justification, in the view of the ESR, is one of the most critical steps in medical radiation protection. Many scientific surveys have clearly shown a deficit in knowledge about the risks of diagnostic imaging among medical professionals, both referring doctors and radiological staff. Creating the awareness of the impact of radiation exposure based on an understanding of the potential effects of x-ray examinations is the first step. Radiologists and clinicians must know the diagnostic potential and the biologic impact of the examinations they request and/or perform; based on this, they will choose the best diagnostic pathway, maybe avoiding radiation exposure by using ultrasound or MRI, maybe using the best $\mathrm{x}$-ray-based imaging test and maybe even by choosing other diagnostic tools.
Justification at the second level has to be evidencebased, applying the scientific results of high-quality studies. However, beyond evidence, all stakeholders (mainly the referring general or specialized physician and the radiologist) should support and use such guidelines; to reach this aim, a consensus-finding project must precede the publication of guidelines (e.g., using an iterative process called the "Delphi procedure"). Finally, even existing and accepted guidelines will not be used unless they are available in clinical situations; a computerized order entry system with integrated decision support should be available to every doctor referring patients for imaging.

Currently, the tool of the Royal College of Radiologists (RCR, UK), called "Making the best use of clinical radiology services," a database developed over many years, is an established solution; unfortunately, it is not accessible on the Internet to non-members. A modified earlier version had been adapted by the EC. The large set of "ACR Appropriateness Criteria" of the American College of Radiology is another widely used source of evidencebased guidelines. The French Society of Radiology and some other European national societies have defined national guidelines; these are available on the Internet; some have not been updated regularly. The ESR is cooperating in a project with the World Health Organization (WHO) and other partners to establish a database that has the support of the referring physicians and will be updated regularly.

Optimization in medicine

Once a radiological examination is justified, optimization is the next challenge. Optimization should follow the ALARA principle (as low as reasonably achievable), and it has to be adapted to each radiological procedure and situation:

- Radiography

- $\mathrm{CT}$

- Fluoroscopy - angiography-intervention (http://www. cirse.org/index.php?pid=412).

- Hybrid imaging (PET-CT, SPECT-cone beam CT)

- Imaging during pregnancy and in childhood as well as young adults

- Imaging in disease requiring periodic follow-up examinations

- Occupational exposure (http://www.cirse.org/files/File/ SOP/Occupational\%20radiation $\% 20$ protection $\% 20$ for $\%$ 20interventionalists\%20FINAL.pdf)

Guidance for other specific optimization measures is available at several websites (see point 12). 
Diagnostic reference levels (DRLs)

According to the ICRP, the DRLs are benchmarks (75th percentile of a patient population), which should not be exceeded in a group of patients of average body size rather than absolute thresholds of individual exposure per examination. There is, thus, no doubt that, in heavy patients or in complex procedures, reaching the DRL should not be a reason to stop the examination or the treatment. Even for fluoroscopically guided interventional procedures, the ICRP recommends the use of DRLs, provided that the complexity of the procedure is taken into account [1].

However, in a collective of patients, the mean exposure has to stay within the DRL. Reasonably, DRLs are established for a country with a relatively homogeneous level of health care. Some international DRLs are summarized in Tables 2 and 3. DRLs have to be adapted to children. These specific data as well as the DRLs for radiography and other examinations are available and regularly updated at websites.

\section{Clinical audit in radiology}

Internal and external audits are an excellent tool to regularly check the degree and quality of implementation of justification and optimization in a radiology department. They contribute to improving the medical processes in general and - since they are not used often yet in Europehave to be introduced in the majority of member states in the coming years. The ESR considerably supports clinical audits through its Audit \& Standards Subcommittee that helps our members implement the European Guidelines on Clinical Audit for Medical Radiological Practices [2].

Quality assurance (QA) program

QA programs are recommended for all diagnostic radiology facilities. A QA program consists of planned and systematic actions providing confidence that a facility will produce consistently high-quality images with minimal exposure. The program has to guarantee periodic checks of all components of a diagnostic x-ray system. It relies on a clear definition of responsibilities of the team members and starts with the specifications of the equipment for purchase. Monitoring and maintenance include a series of tests that can be performed by different assigned people; they are directed to x-ray generation, exposure, detector performance, post-processing and viewing at a workstation. QA programs use different adapted procedures for different radiological procedures and thus will differ for radiography, CT and fluoroscopy. Images are compared to standards of acceptable image quality. In case of a problem, corrective actions must be in place. The QA program is incomplete without records, a manual and systematic training for all persons involved in it. Finally, it has to be reviewed periodically for all components.

The contribution of the ESR to urgent needs in medical radiation protection

- The ESR strongly supports education and training in radiation protection of all medical staff involved with justification and optimization of imaging exams.

- Dissemination of information regarding radiation protection to all European countries (professionals, general population) is one of the primary tasks of the ESR.

- Justification: the ESR takes initiatives and is a strong partner in the cooperation to establish European referral guidelines for imaging.

- Optimization: the ESR supports all efforts to optimize imaging for the individual patient. Standard operating procedures (SOPs) and DRLs for specific exams are important tools in optimization.

- The ESR actively cooperates with international organizations, such as the ICRP, IAEA, WHO, European Commission (EC), International Radiological Quality Network (IRQN), European Medical ALARA Network (EMAN), etc.

European legislation and selected European publications regarding radiation protection

- Safety standards to protect the health of workers and the general public, Directive 96/29/Euratom (currently under revision, to be replaced by one directive containing
Table 2 Stochastic effects, DRLs for CT (EMAN data)

First value $=\mathrm{CTDI}_{\mathrm{Vol}}[\mathrm{mGy}]$, second value $=\operatorname{DLP}[\mathrm{mGy} \times \mathrm{cm}]$

\begin{tabular}{llllll}
\hline Examination & UK & Germany & Belarus & Switzerland & EUR \\
\hline Author & NRPB 67 & BfS & Kharuzhyk & FOPH & MSCT \\
Year & 2005 & 2010 & 2010 & 2010 & 2004 \\
Brain & $65-55 / 930$ & $65 / 950$ & $60 / 730$ & $65 / 1,000$ & $60 / 337$ \\
Chest & $13-14 / 580$ & $12 / 400$ & $20 / 500$ & $15 / 450$ & $10 / 267$ \\
Abdomen & $14 / 470$ & $20 / 900$ & $25 / 600$ & $15 / 650$ & $25 / 724$ \\
Pelvis & $14 /-$ & $20 / 450$ & $25 / 490$ & $15 / 650$ & - \\
\hline
\end{tabular}


Table 3 Stochastic effects, DRLs for fluoroscopy-guided intervention

\begin{tabular}{lll}
\hline Examination & Dose-area product $\left[\mathrm{Gy} \times \mathrm{cm}^{2}\right)$ & Source \\
\hline Coronary angiography & $57(6$ min, 1,270 frames) & Neofotistou et al. [3] \\
Coronary angioplasty & $94(16$ min., 1,355 frames $)$ & \\
Angioplasty (other) & $25(22-27)$ & Marshall et al. [4] \\
Stenting & $56(50-64)$ & \\
Embolization & $160(127-203)$ & \\
Biliary intervention & $66(54-84)$ & \\
ERCP & $16(15-64)$ & \\
Drainage & $36(25-51)$ & \\
\hline
\end{tabular}

all aspects of medical radiation protection): http://ec. europa.eu/energy/nuclear/radioprotection/doc/legislation/ 9629 en.pdf

- Draft new EC Directive on Basic Safety Standards: http:// ec.europa.eu/energy/nuclear/radiation_protection/doc/ art31/2010_02_24_draft_euratom_basic_safety_stan dards_directive.pdf

- Medical Exposure, Directive 97/43/Euratom: http://ec. europa.eu/energy/nuclear/radioprotection/doc/legislation/ 9743 en.pdf

- Public Information, Directive 89/618/Euratom: http:// eur-lex.europa.eu/LexUriServ/LexUriServ.do?uri= CELEX:31989L0618:EN:HTML

- Outside Workers, Directive 90/641/Euratom: http:// eur-lex.europa.eu/LexUriServ/LexUriServ.do?uri= CELEX:31990L0641:EN:HTML

- High Activity Sources, Directive 2003/122/Euratom: http://eur-lex.europa.eu/LexUriServ/LexUriServ.do? uri=CELEX:32003L0122:EN:HTML

- Euratom Treaty, Article 31-Group of experts: http:// ec.europa.eu/energy/nuclear/radiation_protection/ article_31_en.htm

- European Commission Guidelines on Clinical Audit for Medical Radiological Practices (Diagnostic Radiology, Nuclear Medicine, Radiotherapy), RadProt 159, 2009: http://ec.europa.eu/energy/nuclear/radiation_protection/ publications_en.htm

- The Status of the Radiation Protection Expert in the EU Member States and Applicant Countries, study on Education and Training in Radiation Protection, Rad Prot 133, 2003: http://ec.europa.eu/energy/nuclear/ radiation_protection/publications_en.htm

- Guidelines on Education and Training in Radiation Protection, RadProt 116: http://ec.europa.eu/energy/ nuclear/radiation_protection/publications_en.htm

- Guidance on Diagnostic Reference Levels (DRLs) for Medical Exposure, RadProt 109, 1999, [similar to ICRU report 74, 2005]: http://ec.europa.eu/energy/ nuclear/radiation_protection/publications_en.htm
Selected other publications regarding radiation protection

- ICRP Publication 103 (2007) The 2007 Recommendations of the International Commission on Radiological Protection. Ann ICRP 37:2-4.

- ICRP Publication 105 (2007) Radiological Protection in Medicine. Ann ICRP 37:6.

- ICRP Publication 113 (2009) Education and Training in Radiological Protection for Diagnostic and Interventional Procedures. Ann ICRP 39:5.

- ICRP (2011) Statement on Tissue Reactions. Available at www.icrp.org/docs/ICRP\%20Statement $\% 20$ on $\%$ 20Tissue\%20Reactions.pdf

- Miller DL, Vañó E, Bartal G, Balter S, Dixon R, Padovani R, Schueler B, Cardella JF, de Baère T; Cardiovscular and Interventional Radiology Society of Europe; Society of Interventional Radiology (2010) Occupational radiation protection in interventional radiology: a joint guideline of the Cardiovascular and Interventional Radiology Society of Europe and the Society of Interventional Radiology. Cardiovasc Intervent Radiol 33(2):230-9.

- SIR Safety and Health Committee; CIRSE Standards of Practice Committee (2009) Guidelines for patient radiation dose management. J Vasc Interv Radiol 20 (7 Suppl):S263-73

Links

- IAEA, International Atomic Energy Agency, Radiation protection: http://rpop.iaea.org/RPoP/RPoP/Content/ index.htm

- IAEA: http://www.iaea.org/

- ICRP, International Commission on Radiological Protection: http://www.icrp.org

- ICRU, International Commission on Radiation Units: http://www.icru.org

- Radiation protection, European Commission, Energy: http:/ec.europa.eu/energy/nuclear/radiation_protection/ radiation_protection_en.htm 
- EMAN, European Medical ALARA Network: http:// www.eman-network.eu

- EAN, European ALARA Network: http://www.eu-alara. net

Acknowledgements This article was kindly prepared by the ESR Subcommittee on Radiation Protection (Chairman: P. Vock. National Societies Committee Chairman: L. Donoso. Members: J. Damilakis, H. Ducou le Pointe, R. Loose, C. Owens, M. Prokop, I. Rosenberg. Co-opted observers/advisers: E. Vaño (ICRP), C. Cousins (ICRP), A. Meghzifene (IAEA), H. Imhof) on behalf of the European Society of Radiology (ESR). It was approved by the ESR Executive Council in May 2011.

\section{References}

1. International Commission on Radiological Protection (2007) ICRP Publication 105. 2007. Radiological Protection in Medicine. Ann. ICRP 37(6)

2. European Society of Radiology (2011) European commission guidelines for clinical audit: statement by the European Society of Radiology. Insights Imaging 2:97-98

3. Neofotistou V, Vano E, Padovani R et al (2003) Preliminary reference levels in interventional cardiology. Eur Radiol 13:22592263

4. Marshall NW, Chapple CL, Kotre CJ (2000) Diagnostic reference levels in interventional radiology. Phys Med Biol 45:3833-3846 